This item was submitted to Loughborough's Research Repository by the author.

Items in Figshare are protected by copyright, with all rights reserved, unless otherwise indicated.

\title{
Reshaping understandings of teaching-learning relationships in undergraduate mathematics: an activity theory analysis of the role and impact of student internships
}

\section{PLEASE CITE THE PUBLISHED VERSION}

http://dx.doi.org/10.1016/j.Icsi.2014.08.001

\section{PUBLISHER}

(c) Elsevier Ltd

\section{VERSION}

AM (Accepted Manuscript)

\section{PUBLISHER STATEMENT}

This work is made available according to the conditions of the Creative Commons Attribution-NonCommercialNoDerivatives 4.0 International (CC BY-NC-ND 4.0) licence. Full details of this licence are available at: https://creativecommons.org/licenses/by-nc-nd/4.0/

\section{LICENCE}

CC BY-NC-ND 4.0

\section{REPOSITORY RECORD}

Solomon, Yvette, Tony Croft, Francis K. Duah, and Duncan Lawson. 2019. "Reshaping Understandings of Teaching-learning Relationships in Undergraduate Mathematics: An Activity Theory Analysis of the Role and Impact of Student Internships". figshare. https://hdl.handle.net/2134/17223. 


\section{Reshaping understandings of teaching-learning relationships in undergraduate mathematics: an activity theory analysis of the role and impact of student}

internships

This article presents an analysis of an intervention intended to address an aspect of undergraduate mathematics education that is frequently described as a situation of deadlock, between second-year undergraduates who are disillusioned with their university mathematics experience, and mathematics departments which describe many students as lacking interest in, and awareness of, the nature of university-level mathematics and how it is learned: while departments strive to support such students, the extent to which they can do so is often seen as limited. The SYMBoL Project was designed to address this situation in terms of improving dialogue between students and staff through the introduction of undergraduate internships which challenged traditional hierarchical roles and relationships. Using third generation activity theory to analyse the nature and impact of the internship role, we show how the project legitimized the student voice as channelled through that of the interns, created shifts in perceptions of the problem, and began a process of transformational learning about possibilities in undergraduate mathematics teaching. We consider the implications for developing university mathematics teaching within the wider context of tensions across university systems.

Keywords: undergraduate mathematics, activity theory, brokering, staff-student relationships

\section{Background}

This article presents an analysis of an initiative designed to break a longstanding 'deadlock' in undergraduate mathematics education through the introduction of student interns as mediators in second-year teaching and learning relationships. The nature of the deadlock is well-documented, involving high levels of student disillusionment and alienation from the nature, practices and constraints of university mathematics teaching on the one hand (see for example Daskalogianni \& Simpson, 2002; Solomon, 2008), and staff complaints about students' lack of interest, understanding and preparedness for university-level study on the other (see Smith, 2004; Hawkes \& Savage, 2000), a situation which reinforces staff perceptions that there are limits to the support they can offer. The issues were highlighted in the 
Student Experiences of University Mathematics (SEUM) project (Brown, Macrae, Rodd, \& Wiliam, 2005), which tracked students in two research-intensive British universities. Reporting from that project, Macrae, Brown, Bartholomew, and Rodd (2003) found that it was impossible to reliably predict students who would fail two or more modules in their second year on the basis of their pre-university entrance A level Mathematics or Further Mathematics grades, nor was it possible to predict outcomes on the basis of diagnostic testing upon entry. They concluded that "it is difficult to know what more the university could do to support these struggling students" (p.20). Others report similar findings, suggesting the problem is widespread. Daskalogianni and Simpson (2002), in their study of undergraduates in a (different) prestigious UK mathematics department, refer to a 'cooling off' phenomenon as students lost interest, and became increasingly withdrawn in a vicious circle of disillusionment and personal disappointment. Similarly, Goulding, Hatch and Rodd's (2003) survey of trainee teachers' experience of their mathematics undergraduate courses in 65 universities found reports of struggle and lack of support from staff.

Many universities have developed mathematics drop-in centres aimed at addressing the perceived deficit in school-leavers' knowledge (Lawson, Croft \& Waller, 2012), but their impact tends to be limited to first-years, whose problems can be addressed by a range of staff. Support for more specialist second-year material is more difficult to provide in a drop-in context, and problems supporting second-years remain (Croft $\&$ Grove, 2006). The perception noted by Macrae et al (2003) that there is little more that universities can do to ameliorate the situation continues. While students frequently criticise the nature of teaching and learning relationships in university mathematics (Pampaka, Williams, \& Hutcheson, 2012; Solomon, Croft \& Lawson, 2010), instances of fundamental change in these relationships are few and far between. Addressing this, Croft, Solomon and Bright (2008) suggested that student negativity might be ameliorated by improving opportunities for involvement in both peer and expert communities. The project reported here was designed to take this agenda forward by involving students in the expert community in an organised and integrated fashion in the form of internships focussed upon developing teaching and learning by opening up a dialogue between students and staff and becoming involved in the development of resources. In this article we report on this attempt to break the 
deadlock, using activity theory (Engeström, 2001) as an explanatory tool in our analysis of the process and potential impact of this intervention.

\section{University mathematics as interacting activity systems}

Following Ashwin (2009), we suggest that teaching and learning interactions in university can be represented in terms of Engeström's (2001) third generation activity theory, that is to say, in terms of at least two interacting activity systems. An activity system consists of a collection of individual subjects with a shared object for engaging in what they do, achieved via the use of mediating artefacts, which include language and physical tools. Activity is characterised by a division of labour which denotes which members undertake which tasks and produces differences in power and status. Rules are an inherent part of the system, and relate to both explicit and implicit norms and conventions. An important aspect of activity-theoretical analysis is that it should explain and capture processes of continual change; inevitably, a collective involves multiple and potentially conflicting points of view, and the arising contradictions play a central role in development and change. Third generation activity theory focuses on the interaction between activity systems which, significantly, may not share the same object: the potentially contested nature of the object in this situation and the implications for division of labour is of central interest to us here.

As Ashwin (2009) points out, the application of activity theory to higher education requires making some decisions. Some researchers opt to depict the situation - a course module, for example - as a single activity system. However, this entails privileging either staff or student perspectives, or seeing both as part of the same system - but we share Ashwin's view that it seems unlikely that tutors and students share the same object, or that the same rules apply, or that they relate to the same community; for example, Solomon (2007) found that undergraduate mathematics students explicitly reported belonging to a community that was distinct from that of their tutors, an issue pursued more recently by Biza, Jaworski and Hemmi (2014). Ashwin's adaptation of Engeström's (2001) illustration of two interacting activity systems is useful for our purposes in highlighting how the object of the interaction will be different for the academic (teaching object) and the student (learning object) 
and that during the course of their interaction perceptions of that object will change, and may - or may not - develop towards a shared object. Even more importantly for our current purposes, this adaptation points out and draws on the fact that these interacting activity systems themselves interact with other systems. We can view this from the perspective of identity, whereby, for example, an academic member of staff enacts an identity with respect to their role in the undergraduate programme, but they will also have an identity as member of the university, or as a professional mathematician in the international community. This complexity is mirrored in student identities which, as Jaworski, Robinson, Matthews, and Croft (2012) note, will also be based on membership of other activity systems and histories of earlier system membership (notably, schools).

There will be tensions both within and between activity systems. For undergraduates, a primary object may be developing disciplinary knowledge but it will also include being awarded a degree; Hernandez-Martinez et al (2008) note that mathematics students had many different objects in terms of their aspirations for university. For professional mathematicians working in the academy, the object of their activity system will include providing learning opportunities for students but, as we shall see, this may not be their primary concern, being frequently subordinate to another object, producing and publishing research.

Finally, turning to the role of mediating tools and artefacts, while these play a central role in the teaching and learning situation, and may be shared across the two activity systems of students and staff, Ashwin points out a crucial difference in the relationships that each group has with these tools and artefacts: academics choose what topics students will learn, they control learning spaces, and they design and produce learning materials. Although students may also produce their own learning tools, these will not have the same significance.

In the project described here all these elements of interacting systems come to the fore. As a deliberate attempt to bridge the two communities of staff and students via the introduction of interns who would provide a communication channel across the deadlock and build on this to work with staff to produce new teaching and learning artefacts, the SYMBoL project created a space of contradiction and potential change. 
In this article we employ an activity theory analysis to address the following research questions: (1) What role did interns play within the intervention, in terms of their position within two interacting activity systems? and (2) What was the impact of their involvement on participants' perceptions of the problem?

\section{The SYMBoL Project - a boundary crossing setting}

Our study is situated in a research-intensive UK university mathematics department where, in common with others, there are persistent issues with lecture attendance, failure rates and student satisfaction. SYMBoL - Second-Year Mathematics Beyond Lectures - attempted to address this. Established in Spring 2011, continuing through the summer, and into the academic year 2011/12, the challenge was to explore new ways of working in which both students and lecturers could contribute in a shared enterprise, working collaboratively, and taking joint responsibility. SYMBoL's designers aimed to explore what shifts might be brought about by regarding selected undergraduates - the interns (and others they would speak for) - not simply as individuals on the receiving end of lectures but as contributing to and sharing knowledge about their learning environment. The focus was two specific second-year modules, Vector Spaces and Complex Variables, chosen not just because they were historically problematic in terms of attendance and performance, but also because the module leaders were willing to engage in the intervention.

Before the start of the project a team was established which included the module leaders, and a further eight academic staff. A postgraduate researcher gathered substantial qualitative data throughout the internship. This team was augmented by learning technologists and staff from the University's generic teaching centre. The establishment of a team of this size was the cause of some discomfort as we shall see.

The project began with the recruitment, in Spring 2011, of four students to act as paid summer interns on this specific project. Of the cohort of 100 second year mathematics students, eight applied. Selection was based on two main criteria: they should have achieved at least $60 \%$ overall in their first year courses and they should have studied at least one of the target modules in 2010/11. Following interviews by the two course leaders and one additional member of staff, four students were offered and accepted the posts. Their first job was to gather data through student focus groups on what, in 
the students' opinions, did and did not work on the modules, what could be improved and what might be done differently. They carried out this task and presented their findings to the teaching team in a PowerPoint presentation and a written report towards the end of the summer term in 2011. At the end of their second year, the four began their six-week internship working closely with staff, advising on and revising aspects of the modules, suggesting modifications to existing learning resources such as lecture notes, and producing additional resources. They were provided with an open-plan office close to the offices of staff involved. They had access to a range of tools for resource development, and met almost daily with members of the teaching team to share opinions, negotiate changes to resources, and seek advice on resources they were producing. There were many formal, and even more informal, meetings.

The SYMBoL project challenged the status quo of an explicit boundary between staff and students by creating an environment in which they worked together across the boundary in an organised way, most notably in terms of the interns' involvement in the revision and production of teaching and learning resources. It thus created a clear 'boundary zone' (Tsui \& Law, 2007) characterised by multiple perspectives alongside shared elements from both activity systems. For Engeström (2001), such a boundarycrossing context enables various voices to be heard, and contradictions and tensions to be brought to the fore, bringing about 'expansive learning' as existing practices are questioned, resulting in "collaborative envisioning and a deliberate collective change effort" (p.137). Individuals may move or work across the boundary, and in the context of SYMBoL, the four student interns can be seen as boundary crossers whose work included the creation of new learning tools which blended elements of student understandings with staff expertise and which ran against a traditional division of labour.

\section{Methodology}

In this article, we draw on a variety of qualitative data and artefacts created and collected during the interns' initial period of researching student views and the internships themselves. Prior to the internship, the postgraduate researcher carried out in-depth interviews with the two module leaders; the interviews explored their expectations about how they would work with the interns, what barriers they foresaw, 
their expectations for the outcome of the project, and their own experience of being a university mathematician. Six other academics in the department were closely involved with the project and the underlying issues which had led to its development, and these individuals were also asked to respond to an email survey asking for freetext responses to five open-ended questions concerning their expectations for the interns in terms of what learning they would gain, what barriers they anticipated might arise for the interns' involvement, their expectations for their own relationships with the interns, and what personal benefits they expected to gain from the partnership. All responded to this request. The four interns were also interviewed about their perceptions of the problems currently arising in the courses, the potential outcomes of the project, their anticipated roles in working with staff on course redesign and potential barriers to the partnership. The interns themselves facilitated four focus groups with sixteen of the 100 second-year students towards the end of their second year. Based on previous research into undergraduate students' experience of university mathematics indicating that male and female students have different experiences (Solomon, 2007; Solomon et al, 2010), one group comprised only male and one only female students. The two remaining mixed gender groups included an international student and a student who could be described as disengaged. The original intention to form two focus groups solely comprised of (a) disengaged students and (b) international students failed in that insufficient students were recruited. Focus groups were asked to discuss which module aspects helped them to learn and which aspects they would like improved or changed, the reasons why some students became disengaged from mathematics and how lecturers could better reach out to students. The interns analysed their data and fed back in a report and a presentation that they prepared for staff on the student experience.

During the internship two interns described their experiences in a video; all kept weekly diaries and produced final self-reflection reports. The postgraduate researcher kept fieldnotes throughout the internship, recording observations, issues and events. After the internship, the postgraduate researcher conducted individual interviews with the two module leaders on their experience of the project, the perceived benefits for themselves and the interns, and their view on the courses involved and how they might be improved on the basis of the experience. The six other staff were also 
interviewed, focusing on their view of the internships, the benefits for staff and interns, and their views on engaging in a similar process with their own modules. Interviews were audio-recorded and transcribed for analysis. The final data/artefacts collected are listed below, with the coding system that is used in the analysis to indicate the source of data extracts:

1. Interviews with module leaders pre-internship (N=2): PRE-ML1, PRE-ML2

2. Surveys completed by six other academic staff pre-internship $(\mathrm{N}=6)$ : PRE-ACS1, PRE-ACS2 ... PRE-ACS6

3. Interviews with four interns pre-internship (N=4): PRE-I1, PRE-I2 ...PRE-I4

4. Video interview of two interns midway through internship: MID-VID

5. Report and presentation by interns pre-internship: INT-REP

6. Interviews with module leaders post-internships (N=2): POST-ML1, POST-ML2

7. Interviews with six other academic staff post-internships $(\mathrm{N}=6)$ : POST-ACS1, POST-ALCS2 ...POST-ALCS6

8. Researcher fieldnotes for each of the 6 weeks of the internship: FN1, FN2 _... FN6

9. Internship diaries for each of the 6 weeks of the internship, produced by the four interns: DIARY1-4 WK1-6 (ie DIARY2 WK4 = Intern 2's Week 4 diary)

10. Student-produced learning resources; usage data

11. Intern-produced article for HE-STEM newsletter: STEMNL

The data on which we draw are clearly eclectic and complex: they represent multiple voices and audiences involved in the project and need to be seen as dialogic in essence - they have the quality of addressivity (Bakhtin, 1986, p.95). Not all of the data were collected by the researchers, and were not therefore directly influenced by their intentions, since they include the production of artefacts by the interns for particular audiences and purposes. For example, the learning resources (number 10 in the list above) were produced for fellow students, although of course the interns would also be in part addressing their tutors in so doing. The interns' diaries (9 above) were produced for another audience again - in part the researchers, but also in part the interns themselves. The video (4) was addressing yet another audience in terms of talk about the project as a whole directed to mathematics educators outside 
the university, and perhaps to other students. We draw particular attention to the report and presentation prepared by the interns (5), which we treat as data in this article, being an artefact produced by the interns for the department tutors and the project team as part of their role, and representing their interpretation of that role, rather than data directly recording the views of the wider student body itself. Although our methodology enabled a degree of triangulation through the juxtaposition of interns' journals (9) and researcher fieldnotes (8), we focus primarily here on the origins of the data, since its validity and reliability and also its role in the analysis is dependent on its original purpose. To further ensure robustness of our analysis, data were initially analysed independently by the authors, and then collaboratively, to highlight any differences and similarities between interpretations. Initially data driven but then organised around themes from activity theory, the analysis presented here is the result of extensive discussion strengthened by recognition of the differing perspectives of the authors, who comprised one mathematics educator and one postgraduate student researcher, both of whom were closely involved in the project, together with a mathematics educator and an educational researcher who were both located outside of the project.

\section{Analysis}

To address our two research questions on (1) the nature of the internship role and (2) its impact on perceptions of the deadlock, we draw on Engeström's (2001) exposition of the five central principles of third generation activity theory: the activity system, historicity, multi-voicedness, the role of contradictions and tensions, and expansive learning. We have described above how undergraduate mathematics teaching can be seen in terms of two interacting activity systems. However each system and their particular interaction within the project can only be understood within the wider historical and cultural context of teaching and learning mathematics at a researchintensive university, and the even wider context of mathematics pedagogy traditions. Several inherent contradictions and tensions emerge in our analysis of the project as a site of reflection and innovation in practice; we argue that the project created possibilities for expansive learning - a reconceptualising of the activity embracing wider horizons and different objects - thus demonstrating its potential for positive development. 


\subsection{The activity systems}

Of particular interest for our analysis of the role and impact of the interns on perceptions of the deadlock in undergraduate mathematics is the nature of divisions of labour in the tutor and student activity systems, and how these link to the objects of teaching and learning. A dominant transmission teaching model of 'delivery' of high quality content constituted the object as seen by tutors (see also Williams, 2014, in press). Thus Module Leader 2 (ML2), interviewed before the internships, linked teaching to high quality research expertise:

Being a mathematician at the university means first of all for me being a researcher in mathematics. But it also means we are doing university education and this means we are delivering high profile, first class content and teaching that to the students. [PREML2]

The dominance of content expertise was in turn associated with a division of labour delineating the tutor as expert in their field and the student as somewhat passive learner. This is most evident in lectures:

I tend to feel that lectures are very much one-way communication. The interaction is what the tutorials are for. [POST-ACS3]

ACS4 also recognised that his style was traditional, suggesting that the university structure was responsible for this, as did ACS2:

\footnotetext{
In a way, in my teaching so far, I've been quite traditional. In a sense, it comes automatically when you have this lecture and tutorial structure. [POST-ACS4]

Well, I teach lectures more or less in the way I was lectured to, because in a group of 250, there isn't much else I can do. [POST-ACS2]
}

Turning to the undergraduate activity system, a corresponding division of labour emerged through the interns' report in that responsibility for what happens in teaching is ascribed to tutors. Bearing in mind our earlier caveat that the focus group data are filtered through the interns' perceptions of their role, and thus are coloured by their own intentions, we can see from this extract from the written report that students' 
criticisms are interpreted as emphasizing that change needs to come from staff rather than students:

The focus groups felt that there should be a better level of interaction in lectures, for example; open questions, discussions between students and ensuring students' continuous understanding of the content of the lecture. ... in the tutorial, if there were a clearer structure of the problem sheets then students would have a greater understanding..... [INT-REP]

Additionally, students were also reported as suggesting that harder content or more complex examples should be uploaded on to the learning platform in video form, or as line-by-line 'e-proofs', so that they could review them in their own time. However, the interns also chose to report a view that complete lectures should not be available on line because this 'would have a negative impact on attendance', and that attendance would be further encouraged by working through different examples from those in the lecture notes. Tutors' ascribed responsibility also extended to making explicit learning connections for students, as these bullet points from the interns' presentation show:

- In relation to examples, a good format suggested was 'an example already written out which we could follow and then another example which we would write down.'

- Structure to Lecture notes: Chapters by topic and then problem sheets related to that topic. For example: Chapter 2, Gram-Schmidt. Problem Sheet 2, Gram Schmidt. [INT-REP]

\subsection{Historicity}

As we have noted, our setting is a research-intensive university and the mathematics department has a traditional undergraduate degree that emphasises rigorous proofbased mathematics. As is common in research-intensive mathematics departments, staff are recruited from many parts of the world, particularly from Eastern Europe and China, and with a paramount value placed on research expertise. The ethos of the department and the culture and backgrounds of the staff are important, particularly with regard to the role of research in their jobs, and the way their own experiences of being taught influences their teaching. 
ML1's description of his working day provides an insight which matches Ashwin's observations on the tensions within academic activity systems:

It's just research basically. That is the most enjoyable bit. The teaching comes second sometimes close second. I think most people who are employed as university level mathematicians, it is because it is an opportunity to do research. I will be surprised if many people will say anything different. ... I think some people enjoy the teaching aspects more than others. I am one of those who enjoy it. I think there are some who don't. They are prepared to put up with it. [PRE-ML1]

Lecturers were articulate about the relationship between their own teaching and the way in which they themselves were taught. One lecturer (ACS3) commented explicitly on the similarity:

I am fairly conservative about how I teach... It's similar [to how I was taught] in that generally I lecture by writing on the overhead projector. [POST-ACS3]

ML2 also acknowledged that his presentation of mathematics was rather traditional; whilst he did attempt to go beyond mere transmission, this detracted from the time available for the transmission of information which was central to the division of labour that we have already seen:

And I think it is traditional in many ways when it comes to the presentation of mathematics. When it comes to really persuading students that things are interesting, that's probably something that's not very traditional. I really try to intervene, to ask them questions and so on, which is of course taking a lot of time away. [POST-ML2]

Another aspect of historicity is encapsulated in tutors' comments on student 'shortcomings' in attitude, knowledge and understanding, reflecting aspects of the deadlock that are well known to us:

Particularly we need to take this tail of weaker students who get below $40 \%$. We shouldn't lose those of course.. [PRE-ML2]

The problem with this module is that ... some people don't engage with the module and there is a very high failure rate. [PRE-ML1]

I am absolutely convinced that a lot of them are not interested in mathematics - you only have to talk to them. [PRE-ML1] 
It is difficult to produce parallel data which captures historicity in the student system, although student calls for more interactive teaching, closer relationships with staff and a teaching style more akin to that experienced at school are indicative of a desire to reproduce the kind of supportive relationships which can open up mathematics but can also function as perpetuation of reliance on the teacher as expert in the traditional division of labour. This was exemplified in the interns' report which illustrated an oscillation between requests for better relationships and requests for control:

\footnotetext{
Finally, all of the focus groups said that they would value being treated with respect and as adults. They would like to think that lecturers genuinely care about their success and are approachable and available both in office hours and via e-mail. .... students do not like to feel intimidated or patronised. ....Students appreciated continuous assessment similar to Analysis or Scientific Programming, as they found it encouraged attendance and motivated them to work throughout the semester. [INT-REP]
}

\subsection{Multiple voices}

The different motives, traditions, cultures and aspirations held by the various subjects gave rise to multiple points of view both within and between the two activity systems. The data highlight not only some of the issues surrounding the deadlock but also indicate the potential for changes in understandings of the situation: the SYMBoL project enabled and legitimised an explicit multivoicedness which acted as "a source of trouble and a source of innovation, demanding actions of translation and negotiation" (Engeström, 2001, p.136). Prior to SYMBoL no-one would doubt that staff and students would have different points of view. But what the project created was a structure within which the need for staff to hear the student voice was formalised and made public. Of course, staff/student liaison committees are formal structures intended to give students a voice, but this project went significantly further by forcing close encounters at the module-specific level and over a prolonged period. Not all staff were comfortable with this disturbance to the status quo, as we shall see. The interns and staff were placed in an environment where there was the time and space to listen to each other, to negotiate and to plan together new resources and ways of working. The team meetings meant that issues were aired to a wider group of people than would usually have been involved. This meant that staff had to listen and 
respond in a more considered way than they might otherwise have done. We focus here on the effect of this legitimised multiplicity of voices early on in the project.

In the interviews and survey at the start of the project, staff focused on their perspective as teachers, and the necessity (but also perhaps the impossibility, for the expert) of understanding the second-years' 'thought process' and attitudes:

[I hope to gain] Insight into the student thought process, which will hopefully enable us to make some changes to our courses to enable students to understand more. I also hope to gain some insight into new ways of presenting material... [PRE-ACS6] I might gain some useful ideas for how I should teach my own modules. I may also gain better insight into the sort of things that cause difficulty in mathematics. [PREACS3]

It's been a long time since I was 21. People have different attitudes and expectations now. I can hopefully learn something about what they want out of their university careers more than I did. What they want to get out of the whole degree course and specifically what they want to see when they go to a module. [PRE-ML1]

They saw the interns as having a particular role, therefore:

Information can be channelled much [more] easily by students to students... this information flow is very often very effective. [PRE-ML2]

The same tutor speculated further on the nature of the role, in terms of the interns' potential to provide materials which would be better suited to students' partial understandings:

[The solutions which I provide...] are correct but they are not necessarily in the form they would write if they have fully understood the material. Very often they just copy them. The interns could produce solutions which are more adapted to the needs of students - something which is hard for me because I know it so well. [PRE-ML2]

He went on:

They will have an experience of what they found difficult and what was hard to understand. At some point some things were pretty obvious and that is why I did not spend too much time on that. They could feed back to me on that. [PRE-ML2] 
In pre-interviews the interns expressed parallel ambitions for what their input might achieve and how they accepted responsibility for ensuring that the student voice was heard. They believed they would be able to collect more honest answers from students about issues of concern:

\footnotetext{
As students, we should interview students to see what they think because if you have a lecturer who is older they will feel they can't open up to them... if I ask a student how many lectures they go to they will give me the real [true] answer. If someone else [a lecturer] asks them they will push it up. [PRE-I1]
}

They also thought that lecturers should learn from the project:

Some lecturers need a better understanding of what students actually want. [PRE-I1]

Their comments reflect their 'brokering' role, orchestrating student and staff voices, but here one of the interns takes a further step to see himself 'working alongside' a tutor, in a new division of labour:

I think it is a really good experience; you get to work alongside staff in the department; it's good to know them on a one-to-one basis; it's quite a responsibility and I like that; the idea of helping to reform a module... so the lecturers know what the students want and like. [PRE-I1]

The project thus opened up channels of communication by providing space for multivoicedness to be heard, with potential for change as a result. As we have already seen, the interns' account of their fellow students' views was in terms of staff as responsible for teaching and learning deficits, and staff saw student 'lack' or 'weakness' as problems; however staff suggested that they were willing to listen to student views, and moreover to learn. For their part, the interns believed that an important role was to communicate on behalf of the students, but they also expected to aid in the module reform, which was only loosely conceptualized by the tutors at the start of the project. Together with the legitimation of the student voice as something to be heard and responded to, this central activity gave rise to important tensions and contradictions which we explore next. 


\subsection{Contradictions and tensions}

"Contradictions are historically accumulating tensions within and between activity systems" (Engeström, 2001, p.137), and the multiple voices we have heard are indicative of these. Notwithstanding their recognition that interns have a contribution to make, there were tensions evident in the staff's views on the role which they should take. ML2 regarded the interns as both experts and novices in the sense that they had completed the course, echoing his earlier idea that they would be able to provide some sort of communication bridge between the expert (himself) and the second-year students' partial understanding:

I will say they are really both at the same time. They have successfully completed the course - they are much further than the [incoming second-year] students. So they are both experts and novices and that's their strength. We should use it. [PRE-ML2]

However, he was clear that they were not in a position to really contribute to the module design:

There should be very restricted influence of students in the design of the curriculum
simply because they don't have enough experience doing that and very often their
ideas, I don't want to say [they are] naïve, but they are not influenced by experience. [PRE-ML2]

And yet the interns did make a contribution beyond merely acting as a communication channel. Rather than simply providing staff with a window into the second-years' minds, they worked with lecturers to improve existing (lecturer-produced) resources, and to produce new artefacts including handouts and video screencasts which explained solutions in ways which drew attention to potential pitfalls and misunderstandings. As such, they were introducing elements from the undergraduate community into the staff community, thus producing new boundary objects (Star, 1989; Tsui \& Law, 2007). ML2's assertion about what constituted an appropriate division of labour was echoed at the end of the project by ML1, when asked about whether he would have run the project differently. He commented that he would have preferred to work just with the two interns assigned to him, not the wider team, which involved a number of other staff as well: 
I definitely feel there are too many people involved. When it was first brought up, I thought it would be more me and the interns. I think they get confused sometimes because there were different people providing inputs on the subject matter.... I had the feeling, sometimes, that maybe it would have been better if I hadn't had quite so many people telling me what was right and what was wrong. [POST ML1]

And yet, in some ways, this goes to the heart of the matter. There was an intention to disturb the status quo, to encourage staff to reflect on the issues raised and to explore the potential for change, in a way which might not have happened in a traditional master/apprentice role with which they might have been more comfortable. As we have suggested above, the establishment of a wide-ranging team provided a public forum that legitimised the student voice in a stronger way than would have occurred had staff/student working relationships been confined to those immediately involved. The forced attention to contradictions and tensions had the potential to lead to change through explicit debate around pedagogical issues which addressed the assumptions underlying the deadlock.

\subsection{Expansive learning}

Engeström's activity theory suggests that when contradictions mount up, participants within the system, or interacting systems, may begin to question current practices, with an ultimate outcome of expansive learning in which the object of the activity is reframed and the system reconceptualised: "A crucial triggering action in the expansive learning process... [is] the conflictual questioning of the existing standard practice" (Engeström, 2001, p.151). In addressing our question regarding the impact of the internships on perceptions of the problems underlying the deadlock, we can see some indications of expansive learning in the form of reflection on existing pedagogical practices and divisions of labour, and an increased understanding of teaching and learning relationships in undergraduate mathematics which brought historical assumptions about both staff and students into question.

At the outset of the project, staff were likely to see students as either engaged or not, and to have doubts about the interns' role beyond communicating 'how students think'. However, the project caused them to notice pedagogic issues and possibilities 
for re-envisioning of the learning environment which they had overlooked before, as noted afterwards by ML1:

It was fruitful for me, because it focused my attention on certain parts of the notes that had deficiencies, shall we say, and I was able to improve them. So, there definitely was a direct benefit. ... There were some bits that I probably did realise needed improving, but there were other bits that I hadn't appreciated that they weren't being understood.

[POST-ML1]

One staff member remarked that he had not realised that a technique was taught in a particular way in the second-year, and that he would as a consequence modify his first year teaching to smooth the transition. This event was recorded in fieldnotes, where the role of the interns as a catalyst for discussion with the whole team, rather than just a means of communicating second year views, was visible:

Intern 1 asked about whether it was ok in his screencast to write $(6+5 \times 3=6+15=21)$

when working modulo 11 . Is this wrong - should he go immediately to $5 \times 3=4 \_\{11\}$

etc. This opened up a discussion wherein ACS5 talked about equivalence classes.

Different notations were discussed. ACS3 asked about the specific notations used by

ML2, and then suggested he might have to change the notation he used in his [firstyear] module to provide consistency. [FN1]

Despite arguments put forward by both module lecturers against having such a large team involved, it is clear in this instance that this led to positive outcomes in terms of changes to other modules (in this case first-year) which would in turn ease the transition into second-year modules.

On several occasions, staff said that they were surprised at how well the internship worked and how good the students actually were in a working environment: they did indeed have something to offer and contribute to learning:

Both sides put in a tremendous amount of work into making that happen, and that was in some way above my expectations. I expected there to be more problems. ... I wasn't totally sure what they would manage to achieve within that period. They achieved far more than what we had really hoped. [POST-ACS6] 
There was explicit acknowledgement that the existing learning environment failed to turn many students into 'mathematicians', in contrast to the obvious development of the interns:

I was happy to watch those who were students turn into mathematicians over the six weeks, which very few of our students do. [POST-ACS2]

And from the interns' point of view:

I have only really become interested in maths in the past six weeks - for the first time in my life! [STEMNL]

The project discussions and interviews suggested that the students' calls for a more personal relationship were being heard. ACS2 commented:

What can be done to have more interaction between students and staff more widely?

That is something that we're thinking about now. [POST-ACS2]

The change in perspective of interns was also marked. Towards the end of the project, one intern remarked:

Before the internship I was scared to ask a question in lectures because I thought I might be patronised but it turns out that working with the staff has changed my view on this and I now feel I can ask them questions. [MID-VID]

The staff echoed this:

The students [interns] were saying, "We wouldn't have gone to staff before, but we will now." I think that's a success. [POST-ACS2]

Interns also changed their views of the job that staff did:

I have really enjoyed the debates about how people teach - it is interesting to see that lecturers don't agree on things. I have learned that an important purpose of a university is research and that lecturers spend most of their time outside of term time working on their research. [STEMNL]

And at the end of the summer, interns expressed a sense of belonging to the mathematics community: 
The tea hour is a time where I'm feeling more a significant part of the mathematical community where we can bounce ideas off one another. I think the relationships I build in this time will make a difference to my remaining time at uni, as I now see lecturers as more on my level than before. [DIARY2-WK4]

\section{Discussion}

As we noted earlier, activity-theoretical analysis captures processes of ongoing incremental change in moving systems. Importantly, change does not occur simply as a result of putting new structures into place, but develops over time as contradictions arise and are responded to. Furthermore, activity does not occur in a vacuum; third generation activity theory emphasizes overlapping multiple systems, and while we have focused on two here, of course these overlap and intersect with other systems, including institutional-level and sector-level systems in Higher Education. In addressing in particular our second research question regarding the nature and impact of the SYMBoL project on participants' perceptions of the problems which are apparently inherent in undergraduate mathematics education, activity theory has enabled us to situate the project within the history of two systems and to see its role in disrupting established roles and assumptions. At the same time, we can see the project as functioning within a wider nexus of concerns about widening participation and the student experience in England, which contribute to its on-going incremental impact in changing perceptions of the possibilities for addressing problems in undergraduate mathematics teaching.

Our analysis indicates that the SYMBoL project can be described as a boundary zone or boundary-crossing setting, in which there was potential for expansive learning to take place. Against the background of a deadlock in terms of high failure rates and research suggesting that many undergraduates become disenchanted with traditional forms of teaching, the project aimed to encourage questioning and dialogue between students and staff and thereby to enable the department to begin to work towards enhancing the teaching-learning experience. Reflecting on our first research question concerning the interns' role within the intervention, we suggest that it became much more than the communication channel about second-year students' understandings which staff originally envisaged, and that the presence of the interns and their work created tensions which not only brought multiple voices to the fore, but also 
challenged staff perceptions about pedagogy. In terms of our second research question regarding their impact on perceptions of the problem, this challenge resulted in greater staff awareness and a recognition that there were things that they too could learn.

The extent to which the project has broken through the deadlock and promoted the idea of change is not yet clear. We would anticipate that improvements made to resources are now benefiting future cohorts. Staff learned about areas in which their students were having difficulty. The data indicate some sense of a shared purpose, and a changing sense of self, on the part of interns, at least. Although new resources may be seen as indicative of a development towards a shared object, perhaps we might seek evidence of a more general pedagogic change. There has been a modest ripple effect into other modules that may ease the transition into these problematic ones. However, efforts to run the project in summer 2012 with two more second-year modules were hindered because of reluctance amongst other staff to become involved. Nevertheless, interns were employed, three for a third-year module, and two for a second-year module for engineers. Furthermore, elements of the project were adopted at two other research-intensive universities whereby second-year mathematics modules there were subjected to scrutiny and modification by student/staff teams.

In our view, this is all positive: with Ashwin (2009), we note the complexity of interacting systems; the existence of tensions with the wider network of activity systems which interact both historically and contemporaneously with those of university mathematics teaching makes it highly likely that change will be gradual and incremental. Thus while there is pressure from one part of the sector to focus on research, other pressures concern teaching quality; we suggest that the SYMBoL project had an impact in terms of disrupting the traditional division of labour and presenting tutors with a different view of undergraduate mathematics pedagogy, even if that view is not immediately taken up in action. It occurred in a milieu which stresses the need to address a widening participation agenda and also to keep a constant eye on student experience metrics which exert a strong influence on university fortunes. More locally, it took place alongside a Peer Assisted Learning initiative (see Duah, Croft, \& Inglis, 2014), and another aiming to develop a 
'community of inquiry' (Biza et al, 2014); together these activities and wider system objects combine to create a variety of cultural resources on which tutors may draw as they develop their perceptions of the issues in undergraduate mathematics teaching and learning in the future.

\section{Implications}

As we have noted, fundamental changes in the nature of teaching and learning relationships in university mathematics are few and far between, and traditional, entrenched positions which emphasise transmission teaching from expert to novice in a strict division of labour alongside the application of a deficit model to explain struggling students are hard to shift. But one implication of our analysis is that there is potential for gradual change as tutors encounter new practices and pressures. In particular, the disruption of traditional divisions of labour in terms of the separation out of content knowledge expertise and pedagogic design suggests ways forward for future interventions. Although they may well not recognise this as the case, SYMBoL provided a professional development opportunity for tutors that would not have taken place otherwise. As is widely recognised, staff development focused on teaching is difficult to 'sell'; many staff are resistant to engaging with formal opportunities, particularly in research-led university mathematics departments. But beyond this tension, staff development in the area of teaching is often necessarily general rather than specific, with limited use, as ML1 comments:

\footnotetext{
The [professional development courses] that I have been to that are quite useful are the ones that acquaint you with the university regulations and the way the university does things. The ones that I will say are not useful are the ones where they are trying to tell you about teaching because it is just too general. [ML1]
}

In contrast, projects such as SYMBoL provide a different kind of professional development opportunity, involving close collaboration with students themselves and a clear focus on the pedagogic demands of particular content areas. While as we have shown this can lead to tensions, these same tensions indicate ways in which the deadlock might start to be addressed. The extent of staff participation and the strong focus on problem solving presented new opportunities for teaching development in a 
form which was palatable, at least to some mathematicians, in research intensive institutions.

The outcomes of this project suggest a number of further avenues for research. As we have noted, there are multiple small projects in university mathematics departments which aim to develop new pedagogies; of interest for future research is their sustainability beyond the life of individual projects, which are often funded and resourced as in the case of SYMBoL. Lasting development and change is the real target for such interventions, and research is needed which explores how transformational contradictions play out in different interventions in local systems, and the interactive part played by wider system policy as both a driver and a constraint. With regard to our own project, further research will need to assess whether this initiative has had a sustainable impact in terms of expansive learning, but we believe we have shown that it is possible to challenge the status quo and to start to take steps to "better support these struggling students" (Macrae et al, 2003, p. 17).

\section{Acknowledgements}

SYMBoL was funded by the National HE STEM Programme whose contribution is acknowledged. We express appreciation to students and staff who cooperated fully with the research team.

\section{References}

Ashwin, P. (2009). Analysing teaching-learning interactions in higher education: accounting for structure and agency. London: Continuum.

Bakhtin, M. M. (1986). Speech genres and other late essays, (V. W. McGee, Trans.). Austin: University of Texas Press.

Biza, I, Jaworski, B. \& Hemmi, K. (2014, in press). Communities in university mathematics. Research in Mathematics Education, (16)2, pp not yet available.

Brown, M. \& Macrae, S., Rodd, M., \& Wiliam, D. (2005). Full Report of Research Activities and Results: Students Experiences of Undergraduate Mathematics: R000238564. Swindon: Economic and Social Research Council. 
Croft, T., \& Grove, M. (2006). Mathematics support: support for the specialist mathematician and the more able student. MSOR Connections 6(2), 1-5.

Croft, T., Solomon, Y. \& Bright, D. (2008). Developing academic support for mathematics undergraduates - the students' views. Proceedings of the CETL MSOR Conference 2007, 22-7. Birmingham, UK: Maths Stats and OR Network.

Daskalogianni K., \& Simpson, A. (2002). "Cooling off" - the phenomenon of a problematic transition from school to university. Proceedings of the Second International Conference on Teaching Mathematics at the Undergraduate Level, 103-10. Crete, Greece.

Duah, F., Croft, T., \& Inglis, M. (2014).Can peer assisted learning be effective in undergraduate mathematics? International Journal of Mathematical Education in Science and Technology 45(4) pp552-565

Engeström, Y. (2001). Expansive Learning at Work: toward an activity theoretical reconceptualization. Journal of Education and Work 14(1), 133-56.

Goulding, M., Hatch, G., \& Rodd, M. (2003). Undergraduate Mathematics Experience: its significance in secondary mathematics teacher preparation. Journal of Mathematics Teacher Education 6, 361-93.

Hawkes, T., \& Savage, M.D. (2000). Measuring the Mathematics Problem. London: Engineering Council.

Jaworski, B., Robinson, C., Matthews, J., \& Croft, A.C. (2012). An activity theory analysis of teaching goals versus student epistemological positions. International Journal of Technology in Mathematics Education 19(4), 147-152.

Macrae,S., Brown, M., Bartholomew, H. \& Rodd, M. (2003). An examination of one group of failing single-honours students in one university. MSOR Connections $3(3), 17-20$.

Hernandez-Martinez, P., Black, L., Williams, J., Davis, P., Pampaka, M. \& Wake, G. (2008). Mathematics students' aspirations for higher education: class, ethnicity, gender and interpretative repertoire styles. Research Papers in Education, 23(2), 153-165.

Lawson, D., Croft, T., \& Waller, D. (2012). Mathematics support past, present and future. International Conference on Innovation, Practice and Research in Engineering Education EE2012. Available from http://cede.lboro.ac.uk/ee2012/programme papers.html (accessed 9/4/2013). 
Pampaka, M., Williams, J. \& Hutcheson, G. (2012). Measuring students' transition into university and its association with learning outcomes. British Educational Research Journal 38( 6), 1041-1071

Smith, A. (2004). Making Mathematics Count. The Report of Professor Adrian Smith's Inquiry into Post-14 Mathematics Education, The Stationery Office London. http://www.mathsinquiry.org.uk/report/MathsInquiryFinalReport.pdf.

Solomon, Y. (2007). Not belonging: What makes a functional learner identity in undergraduate mathematics? Studies in Higher Education, 32, 79-96.

Solomon, Y. (2008). Mathematical Literacy: developing identities of inclusion. London \& New York: Routledge.

Solomon, Y. Croft, T. \& Lawson, D. (2010). Safety in numbers: mathematics support centres and their derivatives as social learning spaces. Studies in Higher Education 35, 421 - 431.

Star, S. L. (1989). The structure of ill-structured solutions: Boundary objects and heterogeneous distributed problem solving. In L. Gasser, \& M. N. Huhns (Eds.), Distributed artificial intelligence, Vol. II, 37-54. London: Pitman.

Williams, J. (2014, in press). Mathematics education and the transition into higher education - Transmaths demands better learning-teaching dialogue. In T. Croft, M.J. Grove, J. Kyle, \& D.A. Lawson (Eds) Transitions in Undergraduate Mathematics Education A, The University of Birmingham and the Higher Education Academy.

Tsui, A. \& Law, D. (2007). Learning as boundary-crossing in school-university partnerships. Teaching and Teacher Education 23, 1289-1301. 